\title{
An Analysis Of Print Media Advocacy Role For Reduced Infections And Positive Living In People Living With And Without Hiv And Aids- A Case Study Of The Kwayedza Newspaper's Nhau Dze Utano Column.
}

\author{
By Malvern Mugadzikwa, Elliot Muchena \& Peter Chiridza
}

\begin{abstract}
A number of researches done in Zimbabwe have mainly focused on the role of media in educating and bringing awareness to people on issues of HIV and AIDS. Today it is assumed that many communities are aware of the disease and have been educated enough but the media should not stop at that. This study examines print media's advocacy role for people living with and without HIV and AIDS and reduce infections with specific references to Kwayedza newspapers in Zimbabwe. Kwayedza is a weekly newspaper published in Shona one of the largest local language in Zimbabwe. The weekly is owned by the largest newspaper publishers in the country, Zimpapers which is a public entity. The researchers are of the opinion that articles in the Kwayedza newspaper's Nhau Dzehutano (Health Issues) Column play a new role that is of advocacy. The study seeks to analyse the type of news and language used in advocating for HIV and AIDS in the Kwayedza newspaper, to examine the frequency and establish the effects of such news in reducing infections and advocating for positive living in society and evaluate the effects. The study is qualitative and descriptive. The main instruments of data collection will be content analysis of articles from the weekly, focus group discussions and structured interviews. The major findings will show whether the language used by Kwayedza is clear enough to achieve its advocacy role. This will be premised on the fact that the paper is written in a vernacular language spoken by the bigger population of the country and that is spoken in all the ten provinces of the country.
\end{abstract}

\section{INTRODUCTION AND BACKGROUND TO STUDY}

Zimbabwe as a developing country has a number of health challenges. These became even worse during the last two decades when the country started to experience political and economic problems. During the onset of HIV and AIDS in the country, the government came up with many strategies of educating and informing people on this new disease which was killing many people. The media was brought in to assist and a number of programmes were made for both the print and broadcasting media. Great successes were achieved since the majority of the media in the country are public and almost wholly run by the government.HIV is related to simian (monkey) immune deficiency viruses (SIV) and where, how and when SIV crossed to human beings no one knows (Peeters; Courgnaud; Abela, 2001).The disease is a worldly pandemic that has hit the whole globe and as such, developing countries have experienced the greatest HIV and AIDS morbidity and mortality, with the highest prevalence rates recorded in young adults and the middle aged in Sub-Saharan Africa. Global HIV and AIDS Response Progress Report (2011), states that Sub-Saharan Africa continues to bear a disproportionate share of the global HIV burden. In mid2010, about $68 \%$ of all people living with HIV resided in sub-Saharan Africa, a region with only $12 \%$ of the global population. According to the report the 1.9 million people who became newly infected with HIV in 2010 in Sub-Saharan Africa represented $70 \%$ of all the people who acquired HIV infection globally. The report went on to suggest that within the Sub-Saharan region Southern Africa remains with the highest number of infections and that is where Zimbabwe belongs to and the country in the 1990s was amongst those with the largest epidemics in the region. However UNAIDS (2011) states that incidence of HIV infection declined by more than $25 \%$ between 2001 and 2009 including in some of the countries with the largest epidemics in the region. Zimbabwe is the first country in Southern Africa to record a significant, sustained decline in the national prevalence of HIV infection among adults, which fell from $29 \%$ in 1997 to $16 \%$ in 2007. In the capital, Harare, for example, the annual HIV incidence is estimated to have peaked in 1991 at $5.5 \%$ and slowed to $1 \%$ in 2010 . These trends reflect the natural evolution of the HIV epidemic along with changes in sexual behaviour. Increased awareness of AIDS deaths and the country's economic decay appeared to have been the primary factors driving these changes in behaviour.

Despite these records the Southern Africa sub region continues to experience the most severe HIV epidemics in the world. According to UNAIDS (Ibid), one third of all people living with HIV globally in 2009 resided in the ten countries in Southern Africa, as did about forty percent of all women living with HIV. Anke van de Kwaak 2005:65 cited by UNAIDS states that in December 1999, Zimbabwe was estimated to have 1400000 adults 
living with HIV and AIDS (15-49 years) with women being in the majority. Most of the information collected on HIV and AIDS was gathered through pregnant women attending antenatal clinics. Although media campaigns through awareness and education about the disease have reduced the toll of HIV and AIDS related deaths, it is believed the media can be used to bring about strategies that shape the way people respond to and work on HIV and AIDS epidemic issues. This is because almost everyone around the world has been affected by the HIV and AIDS epidemic in one way or the other hence it means everyone knows about it.In Zimbabwe various radio and television programmes are used to educate people on HIV and AIDS. Examples of such programmes include Positive Talk aired on ZBC TV1. Positive Talk is a SAFAIDS production that focuses on community mobilisation covering topics that are linked to HIV and Sexual Reproductive Health (SRHR). Discussions are aimed at information sharing and community mobilisation to increase uptake of services and advocacy regarding various health issues. Thus in this paper the researcher focuses on the print media's advocacy for strategies to lower infections and aim for an HIV and AIDS free community.

\section{THEORETICAL FRAMEWORK AND REVIEW OF RELATED LITERATURE}

The theoretical framework of this study can be understood from the context of how most media messages reach the majority of people especially rural people who are mainly targeted by the Kwayedza newspaper. In most urban areas most people interact directly with the media but for rural areas opinion leaders seem to play a critical role. This study is based on the Two Step Flow Theorywhich suggests that ideas flow from the mass media to opinion leaders and then from them to a wider population that is the masses. In its basic form the theory suggests that opinion leaders pay close attention to the mass media and pass on their interpretation of media messages to others. The theory maintains that audiences are active participants in the communication process. This theory asserts that information from the media moves in two distinct stages. First, the messages go to individuals (opinion leaders) then to the masses. According to Lazarsfeld, (1944), opinion leaders pass on their own interpretations in addition to the actual media content. Opinion leader is an influential person in a certain group who gives details and information to lesser active persons in the group. In communication opinion leaders are those who have access to various media like newspapers, radio sets and even television setsOpinion leaders are quite powerful in getting people to change their attitudes and behaviors. Thus the two step theory refined the ability to predict the influence of media messages on audience behavior, and it helped explain why certain media campaigns may have failed to alter audience attitudes and behavior.

\subsection{News writing and language choice}

Henshall and Ingram (1991) suggest that the main task of a journalist is to help people understand what is happening around them; in their village, in their country and in the world. Most readers will not have the knowledge of one's language, so as a reporter one must simplify it for them. The same authorsnoted thata reporter must be able to examine the most complicated issues and events then translate them into a language which their audience can understand so as to make them continue buying the newspapers and making them understand the important issues in the newspaper.For many newspapers todayworldwide, English is the main language, even in magazines, on radio, television or the Internet. Most newspapers in Zimbabwe are written in English except for Kwayedza and Umthunywa which are written in Shona and Ndebele respectively. In Zimbabwe the main language is Shona hence the researchers decided to look at this newspaper written in Shona. Hence in news writing media houses should choose the right language that have a larger number of audiences and use words and grammar which are most easily understood by readers. McDowell (2001) expressed that a newspaper could be a valuable delivery method when it reaches a large target readersabout new research findings in an area like advocatingfor health issues. Boldt (1987) also suggested that utilizing a newspaper column as a teaching method has the potential of reaching more people at a relatively low cost and overcoming the barrier of time for both the newspapers and its readers. Language is a means of expression and allows a person to participate in community activities (Serpell, 1993). It can be used as a medium of fostering a democratic culture. In this sense, language plays an important role in disseminating news that bring about strategies for positive living in societies that consist of people who are infected and not infected with HIVand AIDS. Hence as it is part of culture the language used by a newspaper like Kwayedza can bring about a culture of advocacy for a HIVand AIDS free community.Every word used in a news story should add to the picture one will be trying to build in the minds of readers. For example when writing about HIVand AIDS the subject is too technical and sensitive especially to those infected by the disease. If the reporter uses an unnecessary, vague or unfamiliar word, the meaning of the storybecomes blurred. If it becomes too blurred, it may give the reader a distorted picture of the facts. This is a form of inaccuracy that is just as bad as putting the wrong facts down on paper. Hence there is need for accuracy in terms of the type of language chosen by the reporter.

\subsection{News frequency}

News frequency is among the factors that give value to news. Lippmann (1990) suggests five factors making events newsworthy that is sensationalism, proximity, relevance, unambiguity and facticity. The author 
noted that, keeping your issue in the news creates public recognition and support, thereby increasing its practical importance. However Galtung and Ruge (1965) differentiated his concept into twelve factors among them frequency and threshold as factors that give news value. According to Loue, Linda and Daniel (2003), monitoring media content is the best element of evaluating media advocacy. This monitoring includes simple counts of newspaper articles on the problem being addressed by the advocacy efforts. Content analysis and measuring the size of the print article or tracking the number of times an article appear in the newspaper can help whether advocacy efforts have been successful in generating the readers' attention and increasethe level of understanding the issue (Treno and Holder 1997).On the other hand the high percentage of articles featuring local conditions on HIV and AIDS in combination with the frequency of almost an article every week indicates that newspapers do perceive HIVand AIDS as an important issue to cover. Hence through these, the articles will get more attention since readers would remain with the curiosity as to why the newspaper takes its precious time and space to cover such a subject.

\subsection{Centrality of print media as a necessary tool for advocacy}

Media advocacy is the strategic used by the mass media to advance a social or public policy initiative. Wallack et al (1993) suggests that media advocacy is based on an understanding of public health problems as primarily social, economic and political. In this case advocacy looks at social, economic and political constraints as vital problems to some health issue. For example on HIV and AIDS the causes might be among others: lack of resources to fund media houses to come up with enough equipment, skilled personnel to initiate vibrant ways and strategies to enhance media advocacy on positive living in people with and without HIV and AIDS.

The goal of media advocacy is not to give people a message but to provide groups with a voice to define problems and promote policy solutions (Erickson et al 1990). It can well be the case for some people that getting a finely crafted message to change their personal behavior will be sufficient to motivate them to do so. But the lesson of public health is that for those most at risk and most in need this will not be the case. Thus, media advocacy should be seen as a complement to, rather than a replacement, for, comprehensive health communication campaigns. Henceforth media advocacy can be more effective than a paid public information campaign in increasing public awareness of any issuesIt is said media advocacy is rooted in community advocacy and its goal is to promote healthy public policies and differs from traditional mass media strategies in many ways (Chapman and Lupton 1994), Ryan (1991) went further saying media advocacy shifts the focus from the personal to the social and from the behavior or practice to the policy or environment It is noted that while the traditional media approaches try to fill the knowledge gap, media advocacy addresses the power gap. Hence improvements in health status are believed to come about primarily from gaining more power over the policy environment rather than simply gaining more knowledge about health behaviors (Ryan, 1991).

\subsection{Advocacy strategies and approaches}

According to Ger and Jan de (2011) advocacy refers to non-violent activities designed to influence policies, practices and behaviour while Buckley (2001) elaborates it as the active support of an idea or cause expressed through strategies and methods that influence the opinions and decisions of people and organisationsThe media have a particular role to play in advocacy initiatives, especially campaign based approaches. Newspapers can bring a mass audience, potentially increasing profile and credibility, as well as bringing good publicity and may contribute to mobilising support (Wolf and Kirsten, 2001). Hence using the media for advocacy requires planning and skills, knowing the media audience, placing stories about positive living among those infected by HIV and AIDS and those not infected.According to the World Health Organization report (2004), advocacy for HIV and AIDS prevention is acombined effort of a group of individuals or organizations to persuade influential individuals, groups and organizations through various activities to adopt an effective approach to HIVand AIDS as quickly as possible. According to the report advocacy also aims at starting, maintaining or increasing specific activities to a scale where they will effectively prevent HIV transmission and assist in the treatment, care and support of people living with HIV andAIDS.

\section{METHODOLOGY}

This study is qualitative because according to Davis (2012) qualitative research is more appropriate in studies where there is a lack of literature and it can also bring out the cause for lack of literature. Qualitative research is one "which produces descriptive data: people's own written or spoken words and observable behaviour" (Bogdan and Taylor, 1975, cited in Marable 2011: 47; www.turtleisland.org). Qualitative research is more appropriate for this study where we seek to come up with information on the role of the media in advocacy in Zimbabwe..Three research instruments were used to carry out the research for this paper. Structured interviews, focus groups discussions and content analysis were used to draw much of the data. Interviews were used for health reporters, focus groups were used for the readers and content analysis to analyse and evaluate how HIV and AIDS stories in the Kwayedza newspaper are used to advocate for positive living among those 
living with and without the disease.The study used content analysis as one of its main research instruments. According to Holsti (1968) content analysis is any technique for making inferences by systematically and objectively identifying special characteristics of messages. Also with content analysis it is possible for researchers to use large files of data and systematically evaluate it (Holsti, Ibid). This has enabled the researchersto pull out relevant information from the newspaper under study consistently. The method of content analysis enables the researchers to include large amounts of textual information and systematically identify its properties, such as the frequencies of most used keywords by locating the more important structures of its communication content. Thus a close analysis of the texts was considered. Berelson (1952) notes that content analysis is important in qualitative research because of several reasons that were also considered by the researchers. He maintains that content analysis looks directly at communication via texts or transcripts, and hence gets at the central aspect of social interaction. Focus group discussions were also because it was targeting societies that read the vernacular newspaper so that the researchers would hear their views and opinions. Morgan (1998), suggests that focus group discussions are important in qualitative research because they work as a standalone method, for research relating to group norms, meanings and processes and that the instrument can be used to clarify, extend, qualify or challenge data collected through other methods. The researchers were the ones who guided, monitored and recorded the discussions so that they could get the subjects' opinion and views in their own languages. Morgan (1998) suggests that focus groups are used for generating information on collective views, and the meanings that lie behind those views. They are also useful in generating a rich understanding of participants' experiences and beliefs. The suggested criteria for using focus groups include language of the participants and thus the researchers discussed the topic under study using Shona language.Lastly interviews were also used. The interviews were structured since they are best suited for engaging in respondent or focus group studies where it would be beneficial to compare and contrast participant responses in order to answer a research question. This type of interviews were used with the purpose of letting the subjects of the study to explore their views, experiences, beliefs and motivations on the topic under study and are most appropriate where little is already known about the study phenomenon or where detailed insights are required from individual participants (Morgan, ibid). In this study five articles were on HIV and AIDS were purposefully selected during the month of February 2014. This was aimed at articles that could covered the issue under study. An interview was done with the newspaper's sole health reporter on the Nhaudzehutano column while two focus group discussions were done rural people in Domboshawa districts on the outskirts of Harare the capital of Zimbabwe.

\section{FINDINGS AND DISCUSSIONS}

The researchers considered and read five stories from which the major finding was that the use of banner topics has a strong impact on advocacy stories. Through these banner topics readers can clearly understand the meaning these stories carry. For example a banner topic Ongororwai pamwechete (Couples must get HIV and AIDS testing together) does not need much of the effort of the readers to understand the whole story, but rather it carries the meaning of the whole story itself. From the focus groups that the researchers conducted, readers revealed that stories in Kwayedza helped their societies a lot in that couples were now getting tested together and openly talking about HIV and AIDS. All the groups pointed out that there are no more stereotypes and discrimination as people were now sharing plates, eating from the same plates with those infected as well as using same toilets and bathrooms unlike before. Also the groups revealed that cases of suicide had greatly reduced from people who would have found out their HIV and AIDS status. From the focus groups the researchers found out that people are now free to talk about HIV and AIDS as a result of the stories they read in Kwayedza. The participants also revealed that they did no longer believe in church prophets who were claiming that people can get healed from the pandemic if only they believe in God and their preaching. For the majority of them taking ARVs was the solution and never to stop as preached by some religious leaders and traditional healers. They cited stories like "NezitaraJesuunopona" (You can get healed in Jesus' name) where the reporter takes a religious approach to capture those who were misled by church leaders and prophets that if they believe in God they will get healed and therefore should stop taking the medication. In the article the reporter strongly warns readers that they should keep on taking their drugs once they are infected despite what their religious leaders say. The focus group discussions also revealed that people were now free to disclose their status in the 'Tishamwaridzane' (Seeking a partner) column because of the articles they read in the 'NhauDzehutano' (Health Issues) column. They gave examples of stories like 'Hausikufambawega' (you are not alone) as examples of stories that play an advocacy role in promoting positivity among those infected and affected by HIV and AIDS. The article 'Hausikufambawega' is a warning to those men and women who try to cheat on their partners whilst they don't know their statuses and those who fail to tell their partners about their HIV positive status. The article articulates that when one is found HIV positive they should know that they are not the only ones suffering from the disease. This column tries to sensitize people that many people are infected so we should openly talk about this.From the interview with the reporter it was also noted that she gets 
information through interaction with people both infected and affected. The reporter said that through the interactions with various people she felt there was still a gap between what people believe about HIV and AIDS and how they are supposed to live positively both the infected and those not infected. The interactions with readers showed her that most of them were ignorant about how people should live positively in a society where some are infected and some are not. It was noted that very isolated cases of stigmatization are still prevalent in some rural areas and hence the need for Kwayedza to continue writing such stories in the vernacular language targeting rural communities. The reporter is mainly motivated to write such stories from the workshops she attends organized by HIV and AIDS related organizations such as National AIDS Council of Zimbabwe, SAFAIDS and other NGOs operating in the country.The researchers have also found that Kwayedza is no longer only playing the general roles of educating, entertaining and informing but have embarked on advocacy. From the analysis of the articles in the newspaper it clearly shows that Kwayedza is playing this role well since many people initially associated it with fictious and funny social issues. For example stories about goblins and witchcraft in both rural and urban areas.However the newspaper has been able to play a unique role of advocacy expected to be published in big daily newspapers such as 'The Herald' and 'The Chronicle' which are the biggest circulating dailies in Zimbabwe. The articles are meant to maintain positive living within the society for both people infected and affected with HIV and AIDS. These articles are not only written in textual form but rather accompanied with pictures to show how real the stories are and this has a strong impact on the readers of the newspaper. The use of banner topics in writing stories by the Kwayedza health reporter has a strong impact on readers. This was also used by the newspaper as a tool to attract readers so that they get deeper into the stories and get the meaning of the articles. Banner topics can also be regarded as a tool for media advocacy because with the reader considering only the topic they can get the meaning of the whole story. "Hausi kufamba uriwega...." (You are not walking alone, 13-19 December 2013) is a topic which clearly indicates how print media are working as the voice of the whole community in accepting those who have alreadybeen infected and affected by the epidemic.The findings of this study show that readers are aware of the HIV articles in their "now popular' newspaper. This is evident through the feedback the newspaper receives in the form of messages from the targeted readers. School children who also read the newspaper show that they are aware of the articles and have been sending poems written on HIV and AID which carry the same messages as that in the articles in Kwayedza. The newspaper's senior management noted that members of the public are aware of the HIV and AIDS articles through the messages of those seeking partners through the 'Tishamwaridzane' column. This is a column where those seeking partners are published giving their contact details and their HIV and AIDS status.

It is clear that the language in the newspaper is acceptable to the audiences since it is vernacular. The language caters for both the educated and the less educated and satisfying its targeted audiences that is those from the marginalised rural areas. Kwayedza also uses standard and simple Shona that is understood by all the Shona dialects.

\section{CONCLUSIONS}

The study shows that the print media are playing an advocacy role in reducing HIV and AIDS infections and maintaining positive living among communities. It was noted that the choice of language used by this newspaper has a strong impact on the readers. Through language choice the medium is being effective since it can attract a lot of positive response thereby achieving its goal. The topics of articles on HIV and AIDS issues in Kwayedza speak louder than the whole body of the story itself. An analysis of the stories showed that they are objective, and represent reality as they drew from accepted evidence. Most of the articles in the newspaper have one theme that is, advocating for the people to accept the situation they are in. The situation is thus, almost everyone has been affected in one way or the other by the epidemic. Kwayedza therefore is assuring various communities that people must get tested for the virus and if they are infected they must accept it rather than living in a dilemma.The researchers also concluded that, articles are very effective and they have an impact which will influence behaviour change in the various communities. This is achieved through the use of banner topics which contain within themselves more than the stories that follow them. The study also observed that all the articles in the period covered were written by one reporter. Kwayedza Newspaper uses Shona which is a vernacular language in disseminating advocacy messages to its audiences. This was an advantage to the newspaper readers since the language is the one spoken by the largest number of readers in the country and almost every community has people who are able to read and write Shona.

\section{REFERENCES}


[1] Dorfman L and Themba M, (1993), Media Advocacy and Public Health: Power for Prevention;Woodruff , Sage Publications, Inc., .

[2] Gerbner, G., Gross, L., Morgan, M., \&Signorielli, N. (1981). A curious journey into the scary world of Paul Hirsch. Communication Research, 8, 39-72.

[3] Gerbner, G. (1972). Communication and social environment. Scientific American, 227, 153-160.

[4] Global HIV/AIDS Response- Epidemic update and health sector progress towards Universal Access Progress Report2011

[5] Holsti O.R (1969), Content analysis for the social sciences and humanities, Philippines, Addison-Wesley Pub. Co

[6] Jacobson J O et al (2011), Regional HIV surveillance of youth MSM through multilevel analysis of RDS studies in Latin America. Sexually Transmitted Infections

[7] Katz, E. (1957). The two-step flow of communication: An up-to-date report on a hypothesis. Public Opinion Quarterly 21 (1): 61-78.

[8] Katz, E., and P. Lazarsfeld. (1955). Personal Influence: The part played by people in the flow of mass communications. New York:Free Press.

[9] Pedian N. S et al (2011), 'HIV prevention transformed: The new prevention agenda, Lancet 398:269-78

[10] UNAIDS, (2008), Epidemiological fact sheet on HIV and AIDS: Lesotho

[11] Viswanath, K., and D. P. Demers. 1999.Mass media from a macro-social perspective. In Mass media, social control, and social change: A macro-social perspective, (ed).D. P. Demers and K. Viswanath, 3-28. Ames, IA: Iowa State Univ. Press.

[12] Viswanath, K and K. M. Emmons. (2006), Message effects and social determinants of health: Its application to cancer disparities. Journal of Communication 56

[13] Wallack, L., L. Dorfman, D. Jernigan, and M. Themba (1993). Media advocacy and public health: Power for prevention. Thousand Oaks, CA: Sage.

[14] Wallack, L and Lori D (1999), News for a Change: An Advocate's Guide to Working with the Media; Woodruff; Sage Publications, Inc.

[15] World Health Organisation, (1988), The Role of the Media in the Prevention and Control of HIV Infection and AIDS. Report on Regional Workshop. Western Pacific: WHO.

[16] WHO, UNAIDS and UNICEF. Towards universal access: scaling up priority HIV/AIDS interventions in the health sector. Progress report 2010. Geneva, World Health Organization, 2010 http://www.who.int/hiv/2010progressreport/report/en/index.html, accessed 15 October 2011)

[17] Newpapers used

[18] Kwayedza 